\title{
Haplotypes that include the integrin alpha 11 gene are associated with tick burden in cattle
}

\author{
Laercio R Porto Neto1,2,3, Rowan J Bunch1,2, Blair E Harrison1,2, Kishore C Prayaga1,2 and William Barendse*1,2
}

\begin{abstract}
Background: Infestations on cattle by the ectoparasite Boophilus (Rhipicephalus) microplus (cattle tick) impact negatively on animal production systems. Host resistance to tick infestation has a low to moderate heritability in the range 0.13 - 0.64 in Australia. Previous studies identified a QTL on bovine chromosome 10 (BTA10) linked to tick burden in cattle.

Results: To confirm these associations, we collected genotypes of 17 SNP from BTA10, including three obtained by sequencing part of the ITGA11 (Integrin alpha 11) gene. Initially, we genotyped 1,055 dairy cattle for the 17 SNP, and then genotyped 557 Brahman and 216 Tropical Composite beef cattle for 11 of the 17 SNP. In total, 7 of the SNP were significantly $(P<0.05)$ associated with tick burden tested in any of the samples. One SNP, ss 161109814, was significantly $(P<0.05)$ associated with tick burden in both the taurine and the Brahman sample, but the favourable allele was different. Haplotypes for three and for 10 SNP were more significantly $(P<0.001)$ associated with tick burden than SNP analysed individually. Some of the common haplotypes with the largest sample sizes explained between $1.3 \%$ and $1.5 \%$ of the residual variance in tick burden.
\end{abstract}

Conclusions: These analyses confirm the location of a QTL affecting tick burden on BTA10 and position it close to the ITGA11 gene. The presence of a significant association in such widely divergent animals suggests that further SNP discovery in this region to detect causal mutations would be warranted.

\section{Background}

Tick infestation has a detrimental impact on animal production and ticks are one of the main vectors of pathogenic micro-organisms of veterinary and zoonotic importance [1,2]. deCastro [3] estimated global economic losses caused by tick and tick-borne diseases to the cattle industry in the range of US $\$ 18$ billion per year.

Tick burdens are influenced by the genetic constitution of the host. Heritability $\left(h^{2}\right)$ estimates of tick burdens due to the ixodid tick Boophilus (Rhipicephalus) microplus in Australia range from $h^{2}=0.13-0.64$ [4-7] depending upon the season and breed of cattle analysed. In the animals used in this study, the heritability was $h^{2}=0.37$ (s.e. $=0.02)$ in the taurine animals and $h^{2}=0.15($ s.e. $=0.10)$ in the Brahman animals $[8,9]$. Generally animals of zebu ancestry such as the Brahman carry an order of magnitude fewer ticks than animals of pure taurine origin such

* Correspondence: Bill.Barendse@csiro.au

${ }^{1}$ Cooperative Research Centre for Beef Genetic Technologies, University of New England, Armidale, NSW 2351, Australia

Full list of author information is available at the end of the article as the Hereford or Charolais [10-12]. Twenty one days after artificial infestations of 20,000 tick larvae, Brahman breed cattle will carry around 100 engorged ticks while taurine cattle will carry between 1-2 thousand engorged ticks [10].

Previous genetic studies found that the bovine leucocyte antigens (BoLA) were associated with tick burden $[13,14]$ and these associations have more recently been confirmed using DNA polymorphisms [15-17], but the same allele has not always been associated with reduced tick numbers limiting the use of those markers in different populations. Whole genome scans using DNA microsatellites in linkage analyses have identified a small number of QTL associations $[18,19]$ and a low density genome wide association study (GWAS) identified single nucleotide polymorphisms (SNP) associated with tick burden in several regions of the genome [20]. So far, no DNA marker or haplotype has shown a consistent effect across different breeds for the number of ticks that animals carry. Bovine chromosome 10 (BTA10) was found linked to tick burden in both a microsatellite whole 
genome scan and a low density GWAS $[18,20]$. In that GWAS, three SNP (rs29025985, rs29025981 and rs29025982) at approximately $15 \mathrm{Mb}$ in the Btau 4.0 assembly [21] were associated with tick counts.

To determine whether the region on BTA10 ( 15 Mb) showed significant associations to tick burden, two cattle samples 1) taurine dairy cattle of the dairy tick experiment (DTE) and 2) zebu and zebu-derived beef cattle from northern Australia in the tick zone, consisting of Brahman (BRM) and Tropical Composite (COM) cattle were used. We genotyped 17 SNP in the DTE sample and 11 of them in the BRM and COM samples, including 2 SNP from the GWAS [20] and SNP we identified from sequencing part of the ITGA11 (Integrin alpha 11) gene. Our aims were to replicate the association of the BTA 10 region to tick burden in independent samples, determine whether it was found in different types of cattle, estimate the size of the genetic effect in a large sample, and narrow down the region associated with tick burden.

\section{Results}

We collected SNP from a variety of databases and sequenced part of the ITGA11 gene to identify more SNP. We identified $26 \mathrm{SNP}$ in ITGA11 by sequencing exons 6-9 and adjacent introns in 16 animals from 4 different breeds. There were no differences in the coding sequence between taurine animals but there was one synonymous mutation segregating in BRM animals (Additional file 1). We chose 3 of the 26 SNP for further analysis based on their distribution across the sequenced region and minor allele frequency in all breeds of the panel sequenced. Some of the SNP from public databases were not polymorphic in any individuals in our sample. Of the 16 SNP used from the genome assembly database $\mathrm{ftp}: / /$ ftp.hgsc.bcm.tmc.edu/pub/data/Btaurus/, 15 were monomorphic when genotyped in the DTE, BRM and COM animals and may be sequencing artefacts [22]. This resulted in 17 SNP that were genotyped using the DTE animals and 11 SNP genotyped using the BRM and COM animals (Table 1). Of these SNP, rs29025980 showed a highly significant $(P<0.0001)$ departure from Hardy Weinberg Equilibrium (HWE) in almost all groups tested (5 out of 8 breed types). Apart from rs29025980, deviations from HWE occurred at a low rate (14 out of 124 comparisons) and no more than 2 breed types were significantly out of HWE.

There were significant allele and haplotype frequency differences between the DTE, BRM and COM animals. Allele frequencies for 9 of the 11 SNP were significantly different $(\mathrm{P}<0.05)$ in the three groups of animals (Figure 1). The average $\mathrm{r} 2$ between all SNP in the region was similar in all breeds, $\mathrm{r} 2=0.16$ (DTE), 0.13 (BRM) and 0.15 $(\mathrm{COM})$. The haplotype frequencies were also significantly $(P<0.05)$ different between groups. Nevertheless, there was some evidence of haplotype blocks in the same genetic region that contained ITGA11 (Figure 2 and additional file 2). The size of the haplotype block was smallest in BRM $(<1 \mathrm{~kb})$ and largest in COM cattle $(59 \mathrm{~kb})$.

Four SNP were significantly associated with tick burden $(P<0.05)$ in the DTE sample, including both of the SNP used in the previous GWAS [20] (Table 2, Figure 1). The distribution of the SNP along BTA10 is shown in Figure 3. The most significant SNP were rs29025981 $(P=0.0052)$ and ss161109814 $(P=0.0188)$, the latter of these is from the ITGA11 gene. rs29025981 explained the most residual variance of $R^{2}=0.9 \%$.

Four of the 11 SNP genotyped in the Brahman and Tropical Composite cattle were significantly $(\mathrm{P}<0.05)$ associated with tick scores (Table 2). Two of the SNP were from the genome assembly and two were from sequencing the ITGA11 gene. One of these, ss161109814, had been significantly $(\mathrm{P}<0.05)$ associated with tick counts in the DTE sample. ss161109814 accounted for $1.2 \%$ of the residual variance (R2), another SNP (rs29023639) accounted for more but this SNP was significant in a small sample (COM) and was therefore possibly overestimated in amount of variance explained (Table 2). However, a different allele for ss161109814 was favourable for tick score in the Brahman and Tropical Composite sample (Table 2) compared to the DTE result.

In all samples of cattle there were highly significant $(P<$ 0.001 ) associations between haplotypes using either a haplotype of 10 SNP that includes the ITGA11 gene or for several of the 3-locus haplotypes that are a subset of the 10 SNP (Table 3 and additional files 3 and 4). The 3-locus haplotypes that include SNP from the ITGA11 were significantly associated with tick burden in the DTE $(\mathrm{n}=4)$ and in the BRM $(n=6)$ samples. Many of these associations remained significant after Bonferroni correction of the significance threshold. Although many of these highly significant associations were for relatively rare haplotypes, where no animal homozygous for the haplotype was found, in five of the 3-locus haplotypes that were highly significantly $(\mathrm{P} \leq 0.0053)$ associated with tick burden there were two or more individuals that had two copies of the haplotype. Three of these comparisons were for taurine animals and two were for the BRM animals. Four of these haplotypes also showed some similarity of structure between samples - they show the allele ' 1 ' at the 8 and $9^{\text {th }}$ loci of the haplotypes in the BRM sample and the same alleles at those positions in the DTE sample. There was a low genotyping completion of locus 10 in the DTE sample, so haplotype analyses were run without that SNP in the DTE sample. The haplotype "h3" formed by the 8, 9 and $11^{\text {th }}$ loci was significantly associated with tick burden with its significance exceeding the Bonferroni correction threshold in the DTE and BRM samples. The favourable haplotype of these 3 loci $(8,9,11)$ was common in BRM 
Table 1: Description of markers tested in dairy and beef cattle samples

\begin{tabular}{|c|c|c|c|c|c|c|}
\hline Locus & Position Btau4.0 & Ref 1 & Sample ${ }^{2}$ & $\mathbf{N}^{3}$ & $p_{0}{ }^{4}$ & $\begin{array}{l}\text { HWE5 } \\
\text { p-value }\end{array}$ \\
\hline rs29027392 & 9844454 & BTA & DTE & 820 & 0.03 & $\begin{array}{c}0.0080 \\
\text { (1 breed) }\end{array}$ \\
\hline rs41613225 & 9874407 & BTA & DTE & 820 & 0.34 & $\begin{array}{c}0.0103 \\
\text { (1 breed) }\end{array}$ \\
\hline rs41664397 & 11938389 & BTA & DTE & 820 & 0.15 & $\begin{array}{c}0.0053 \\
\text { (1 breed) }\end{array}$ \\
\hline Ars-BFGL-NGS-70946 & 14471603 & Illumina & DTE & 819 & 0.38 & $\begin{array}{c}0.0173 \\
(1 \text { breed })\end{array}$ \\
\hline \multirow[t]{3}{*}{ rs 29025980} & 14925193 & BTA & DTE & 875 & 0.23 & $\begin{array}{c}<0.05 \\
\text { (3 breeds) }\end{array}$ \\
\hline & & & BRM & 525 & 0.05 & $1.34 \mathrm{e}-38$ \\
\hline & & & COM & 196 & 0.27 & $2.36 \mathrm{e}-24$ \\
\hline \multirow[t]{3}{*}{ rs43616884 } & 14937129 & BTB & DTE & 915 & 0.28 & ns \\
\hline & & & BRM & 546 & 0.05 & 0.0277 \\
\hline & & & COM & 207 & 0.20 & ns \\
\hline \multirow[t]{3}{*}{ rs29025985 } & 14943961 & BTA (GWAS) & DTE & 812 & 0.68 & ns \\
\hline & & & BRM & 464 & 0.09 & ns \\
\hline & & & COM & 186 & 0.37 & ns \\
\hline \multirow[t]{3}{*}{ rs29025981 } & 14944238 & BTA (GWAS) & DTE & 859 & 0.32 & $\mathrm{~ns}$ \\
\hline & & & BRM & 517 & 0.91 & ns \\
\hline & & & COM & 201 & 0.63 & ns \\
\hline \multirow[t]{3}{*}{ rs41594962 } & 14979585 & BTA & DTE & 1042 & 0.29 & $\begin{array}{c}0.0256 \\
\text { (1 breed) }\end{array}$ \\
\hline & & & BRM & 545 & 0.01 & ns \\
\hline & & & COM & 207 & 0.20 & ns \\
\hline \multirow[t]{2}{*}{ ss161109814 } & 14996440 & This paper & DTE & 1037 & 0.40 & $\mathrm{~ns}$ \\
\hline & & & BRM & 526 & 0.06 & $\mathrm{~ns}$ \\
\hline
\end{tabular}


Table 1: Description of markers tested in dairy and beef cattle samples (Continued)

\begin{tabular}{|c|c|c|c|c|c|c|}
\hline & & & COM & 205 & 0.24 & $\mathrm{~ns}$ \\
\hline \multirow[t]{3}{*}{ ss161109807 } & 15002496 & This paper & DTE & 1027 & 0.28 & ns \\
\hline & & & BRM & 525 & 0.62 & ns \\
\hline & & & COM & 210 & 0.49 & ns \\
\hline \multirow[t]{3}{*}{ ss161109797 } & 15003391 & This paper & DTE & 1032 & 0.04 & $\begin{array}{c}0.0337 \\
\text { (1 breed) }\end{array}$ \\
\hline & & & BRM & 526 & 0.05 & ns \\
\hline & & & COM & 212 & 0.03 & ns \\
\hline \multirow[t]{3}{*}{ rs29023635 } & 15034937 & BTA & DTE & 914 & 0.69 & ns \\
\hline & & & BRM & 549 & 0.06 & ns \\
\hline & & & COM & 213 & 0.41 & ns \\
\hline \multirow[t]{3}{*}{ rs29023639 } & 15035100 & BTA & DTE & 296 & $<0.01$ & ns \\
\hline & & & BRM & 548 & $<0.01$ & ns \\
\hline & & & COM & 181 & 0.01 & ns \\
\hline \multirow[t]{3}{*}{ rs29014770 } & 15102776 & BTA & DTE & 901 & 0.68 & ns \\
\hline & & & BRM & 544 & 0.99 & ns \\
\hline & & & COM & 202 & 0.72 & ns \\
\hline rs41657550 & 17147707 & BTA & DTE & 820 & 0.68 & ns \\
\hline Ars-BFGL-NGS-25507 & 18216232 & Illumina & DTE & 819 & 0.75 & $\begin{array}{c}<0.05 \\
\text { (2 breeds) }\end{array}$ \\
\hline $\begin{array}{l}1 \text { Database in which the mar } \\
\text { - significant markers at the } \\
2 \text { DTE - dairy tick experimen } \\
{ }^{3} \text { Number of individuals test } \\
{ }^{4} \text { Frequency of the allele clo } \\
{ }^{5} \text { Hardy-Weinberq equilibriu }\end{array}$ & $\begin{array}{l}\text { cribed, BTA- } \\
\text { association s } \\
\text { han, COM - Tr } \\
\text { alphabet. }\end{array}$ & $\begin{array}{l}\text { reed SNP, BT } \\
\text { posite. }\end{array}$ & nome & y SNP, I & ina - Bo & NP50 ${ }^{\circ}, \mathrm{GWA}$ \\
\hline
\end{tabular}

and rare in DTE cattle. In the DTE sample, the most significant 3-locus common haplotype ("6,7,8 h1") accounted for $1.25 \%$ of the residual variance $\left(R^{2}\right)$ (Table 3). In the BRM sample, the most significant 3-locus common haplotype ("8,9,10 h5") accounted for $1.83 \%$ of the residual variance $\left(R^{2}\right)$ (Table 3$)$. The significant haplotypes that are relatively common (i.e. with more than 2 individuals homozygous for the rarer haplotype) in our samples had haplotype substitution effects of the same, negative, sign in all cases. 

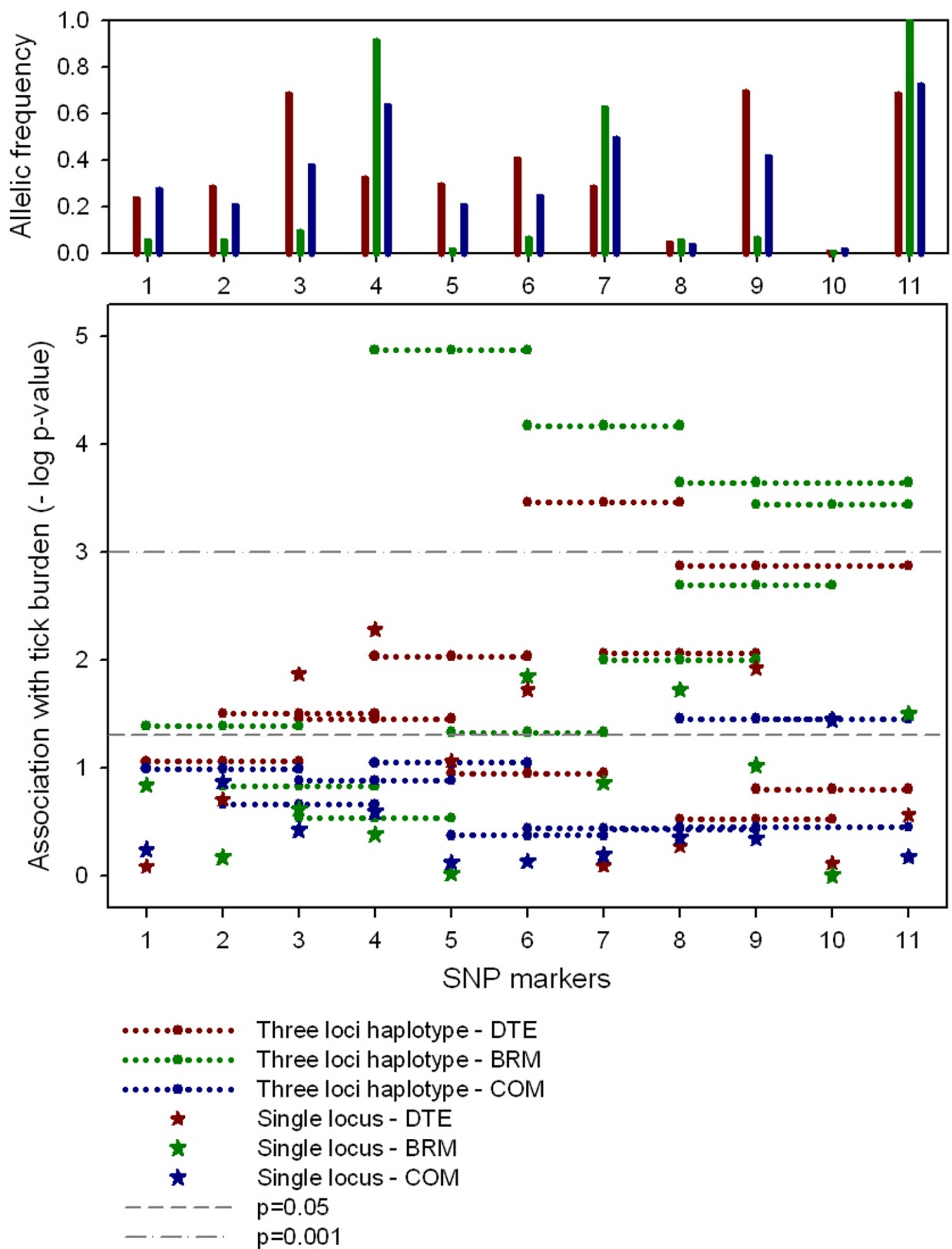

Figure 1 SNP markers at the ITGA11 gene region: allelic frequency and analyses of marker association with tick burden in the three populations. 1- rs29025980, 2- rs43616884, 3- rs29025985, 4- rs29025981, 5- rs41594962, 6-ss161109814, 7-ss161109807, 8-ss161109797, 9- rs29023635, 10- rs29023639, 11- rs29014770. 


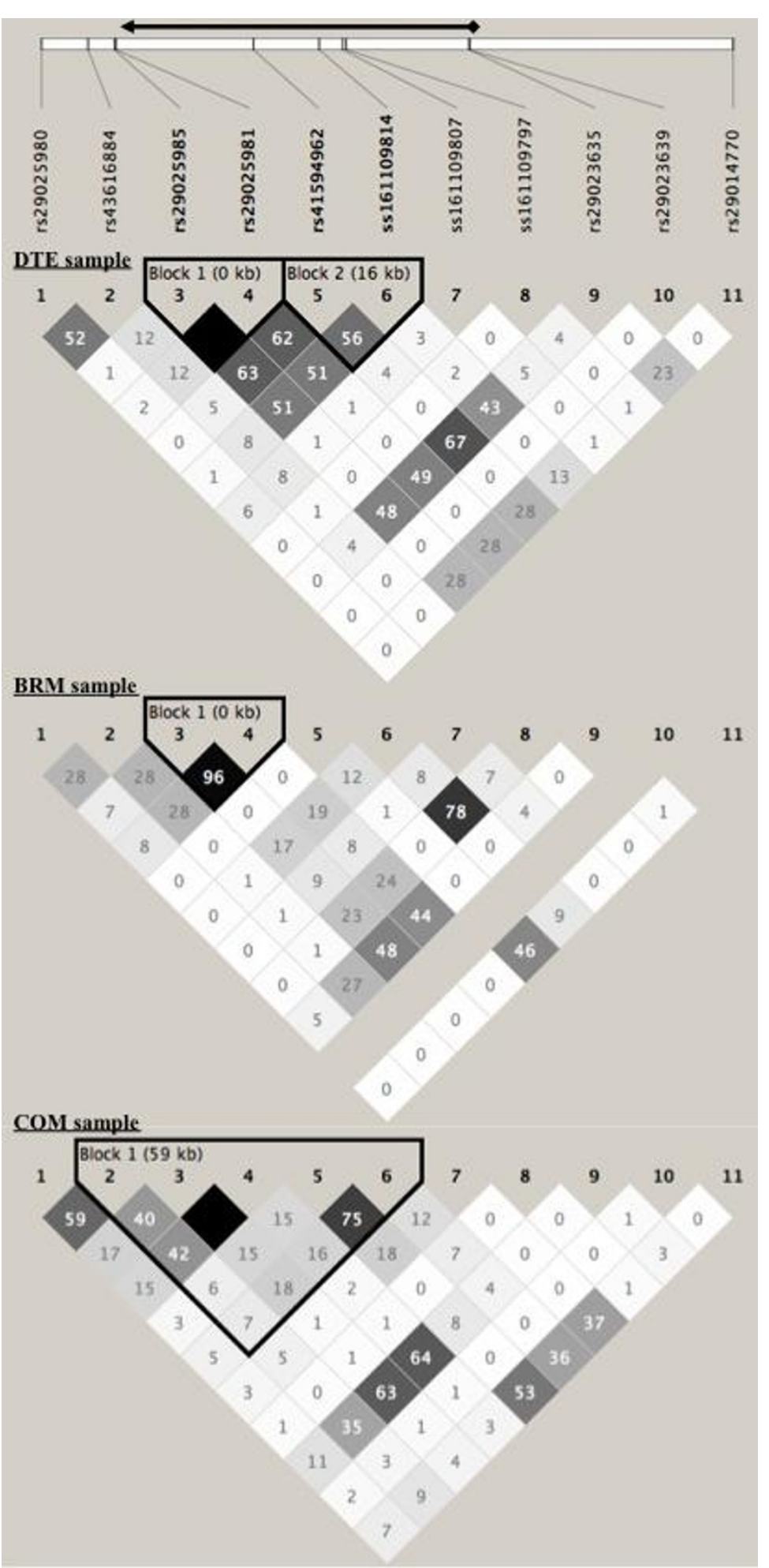

Figure 2 Linkage Disequilibrium (LD), $\mathbf{r}^{2}$ values, between all markers at the ITGA1 1 gene region. The black arrow on the top represents the relative position of the ITGA11 gene. 
Table 2: Significant SNP markers at the ITGA11 gene region associated with tick burden

\begin{tabular}{|c|c|c|c|c|c|c|c|}
\hline Locus & Sample ${ }^{1}$ & $\mathbf{N}^{2}$ & $p_{0}^{3}$ & $\mathbf{R}^{24}$ & $\mathbf{a}^{5}$ & SE6 & p-value \\
\hline rs29025985 & DTE & 812 & 0.68 & 0.0075 & -0.131 & 0.053 & 0.0135 \\
\hline rs29025981 & DTE & 859 & 0.32 & 0.0091 & 0.147 & 0.053 & 0.0052 \\
\hline \multirow[t]{2}{*}{ ss161109814 } & DTE & 1037 & 0.40 & 0.0053 & 0.109 & 0.046 & 0.0188 \\
\hline & BRM & 526 & 0.06 & 0.0115 & -0.309 & 0.125 & 0.0140 \\
\hline ss161109797 & BRM & 526 & 0.05 & 0.0105 & -0.332 & 0.141 & 0.0188 \\
\hline rs29023635 & DTE & 914 & 0.69 & 0.0069 & -0.127 & 0.05 & 0.0119 \\
\hline rs29023639 & COM & 181 & 0.01 & 0.0244 & -1.476 & 0.698 & 0.0359 \\
\hline rs29014770 & BRM & 544 & 0.99 & 0.0085 & 0.601 & 0.279 & 0.0317 \\
\hline $\begin{array}{l}{ }^{1} \text { DTE - dairy tick e } \\
2 \text { Number of indivi } \\
{ }^{3} \text { Frequency of the } \\
{ }^{4} \text { Proportion of res } \\
{ }^{5} \text { Allele substitutio } \\
{ }^{6} \text { Standard error o }\end{array}$ & $\begin{array}{l}\text { ent, BRM - } \\
\text { tested. } \\
\text { closer to A } \\
\text { ariance exp } \\
\text { t in pheno }\end{array}$ & $\begin{array}{l}\text { man, COM } \\
\text { e alphabet. } \\
\text { ed. } \\
\text { standard d }\end{array}$ & cal Com & for the DTE & ick score for & and COM). & \\
\hline
\end{tabular}

\section{Discussion}

In this study we have confirmed that there is a QTL affecting tick burden on BTA10. There were significant $(P$ $<0.05)$ single marker associations to tick burden in DTE, $\mathrm{BRM}$ and COM animals which were more significant $(P<$ $0.001)$ when these markers were analysed as haplotypes. This included haplotypes that incorporated DNA variation from the ITGA11 gene. One of the SNP was significant $(P<0.05)$ in both taurine and zebu animals but the favourable allele was different in effect size and direction. A different favourable allele in two populations is likely to be due to either a spurious association between the trait and the genotypes or due to different patterns of linkage disequilibrium in the two samples between markers and the causative mutation.

Where populations are similar and genetically closely related, different favourable alleles in two samples may be spurious. However, the ancestors of zebu and taurine cattle were separated for more than half a million years before domestication [23], so their population haplotypes are not expected to be similar. Furthermore, an analysis of LD and haplotype structure in the breed types showed that allele and haplotype frequencies were very different between these cattle types in this genetic region. This suggests that LD relationships would likely be different between SNP and that the difference in favourable allele for the SNP ss161109814 could be due to differences in $\mathrm{LD}$ and not due to spurious association. Indeed, it is possible, with such a large evolutionary distance from the common ancestor to these two separated groups, for the causative mutations to be different in these two breed types. In the haplotype analyses, for the relatively common haplotypes that were highly significant in the DTE and BRM cattle samples, haplotypes with the ' 1 ' allele at SNP positions 8, 9, 10 and 11 were significant and showed a similar favourable effect, of -0.21 and -0.27 phenotypic standard deviations respectively (Table 3 ). More importantly, the favourable form of the haplotype was common in the BRM sample but rare in the DTE sample, consistent with the relatively low tick numbers on BRM cattle and high tick numbers of DTE cattle [8-10].

The amount of the variation explained by the markers $\left(R^{2}\right)$, estimated by single SNP or through haplotypes, is approximately $1 \%$ of the residual variance in moderate to large samples. Some of the rarer haplotypes have effect sizes of $>1$ phenotypic standard deviation, but as these involve a small number of heterozygous genotypes these effect sizes have been discounted as likely due to sampling effects. Haplotypes are more likely to reflect the size of effect of a causal mutation than most single markers that are in LD to the causal mutation(s), because recombination takes longer to degrade the relationship between 


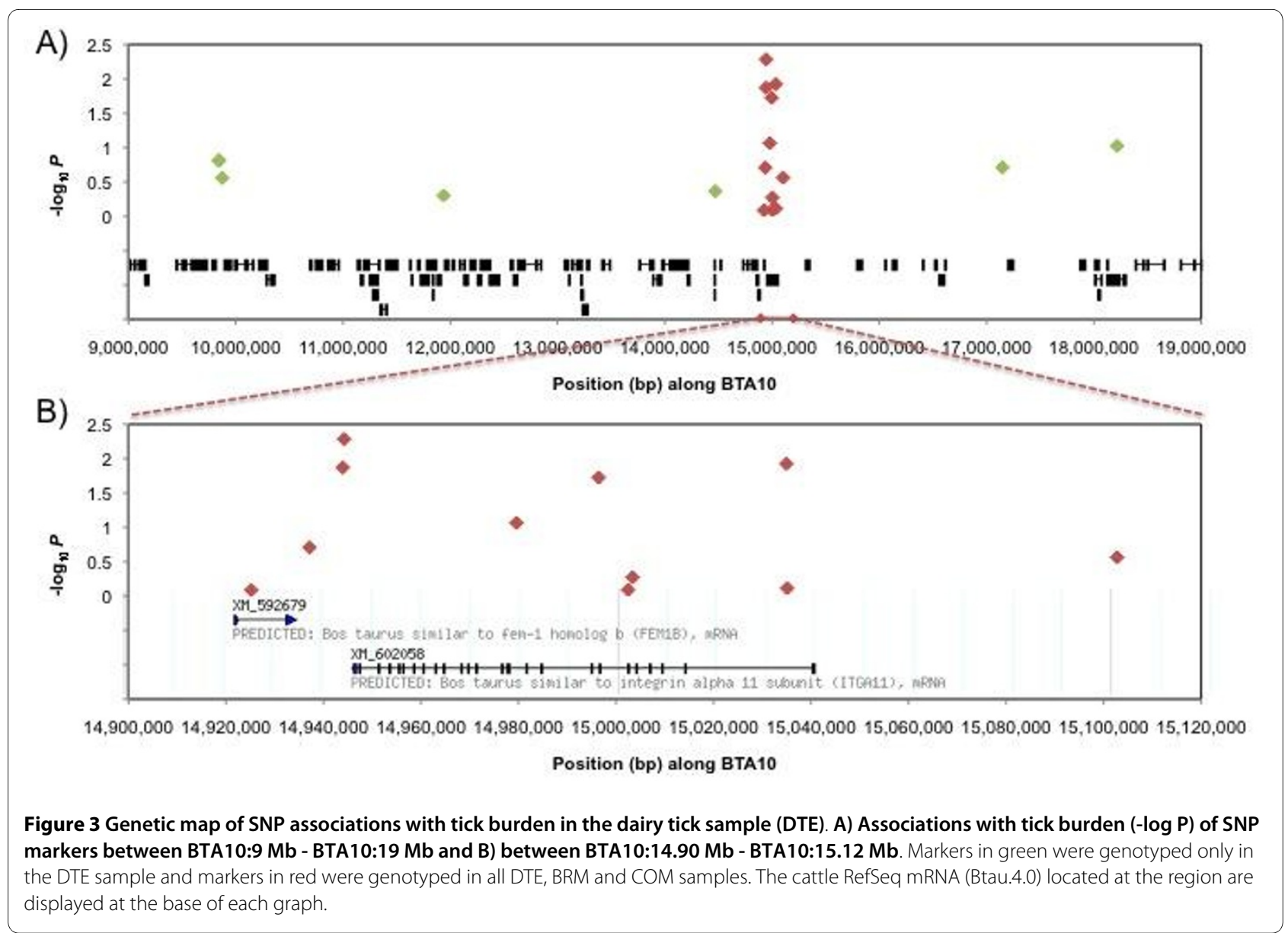

a causal allele and a haplotype than to a single SNP. Further research might determine whether the effect of a causative mutation is large, as shown for some of the haplotypes or, more likely, are relatively small as shown by the more frequent haplotypes. Mutations accounting for a small proportion of the genetic variation $\left(R^{2}\right)$ are commonly identified in QTL mapping studies in cattle and other species. However, it is not yet definitively shown whether causative alleles for these smaller QTL are common variants that have small effects or are due to a large number of very rare QTL each of relatively large effect [24]. Further discovery of new genetic variation will be needed to identify such putative causative mutations which appear to be located near the ITGA11 gene.

The adaptive immune system has long been shown to be important in tick resistance in cattle $[25,26]$, and ITGA11 is neither a part of the adaptive immune system nor known to be part of the innate immune system. In this region the nearest genes that are part of the immune system are PIAS1 (protein inhibitor of activated STAT, 1, BTA10:14,721,762) and ANP32A (acidic (leucine rich) nuclear phosphoprotein 32 family, member $A$, BTA10:15,806,500). In the previous GWAS [20], SNP near those genes were not significantly associated with tick burden. Moreover, the significant SNP in this study are more than $200 \mathrm{~kb}$ from PIAS 1 and nearly $1 \mathrm{Mb}$ from ANP32A. Genotyping of SNP in this study over the 8.4 $\mathrm{Mb}$ of this region of BTA10, which includes these genes, failed to find a signal of association in other parts of the chromosomal segment at the density we used. Our estimates of LD in this region in these samples show low values, consistent with other studies of samples with multiple breeds [27]. Although we cannot categorically reject the influence of those genes, it is unlikely that the significant associations that we found is due to LD to those genes of the adaptive immune system.

Although ITGA11 is not an obvious positional candidate gene for tick burdens, because its biological role appears to be mainly in the control of cellular adhesion and migration, it cannot be rejected completely based on its function. Coelho et al. [28] identified ITGA11 as an interferon-inducible gene in human fibroblasts. It is possible that ITGA11 may play a role in modulating cellular immune responses, by influencing the recruitment and adhesion of immune cells at sites of infection, or ectoparasite infestation. Moreover, the integrity and composition of the dermis may play a role in an animal's defences against ticks. Integrins specifically interact with collagen. 
Table 3: Significant haplotypes of markers at the ITGA11 gene region associated with tick burden

\begin{tabular}{|c|c|c|c|c|c|c|c|c|c|}
\hline SNP1 & Code & Sample $^{2}$ & $\mathrm{NO}^{3}$ & N1 & N2 & $\mathbf{R}^{24}$ & $a^{5}$ & SE6 & p-value \\
\hline $\begin{array}{c}10 \text { snp } \\
\text { h10 }\end{array}$ & $110111111-0$ & $\begin{array}{l}\text { DTE } \\
(48)\end{array}$ & 605 & 17 & 0 & 0.0146 & -0.738 & 0.243 & 0.0025 \\
\hline $\begin{array}{c}\text { 10snp } \\
\text { h19 }\end{array}$ & $111000111-0$ & $\begin{array}{l}\text { DTE } \\
(48)\end{array}$ & 582 & 38 & 2 & 0.0131 & -0.432 & 0.151 & 0.0043 \\
\hline $\begin{array}{c}10 \text { snp } \\
\text { h23 }\end{array}$ & $111010101-0$ & $\begin{array}{l}\text { BRM } \\
(24)\end{array}$ & 419 & 4 & 0 & 0.0422 & 2.119 & 0.492 & $2 \times 10^{-5 \wedge}$ \\
\hline \multirow[t]{2}{*}{$\begin{array}{c}4,5,6 \\
\text { h7 }\end{array}$} & - - - $010----$ & $\begin{array}{l}\text { DTE } \\
(8)\end{array}$ & 808 & 23 & 1 & 0.0082 & -0.507 & 0.194 & 0.0092 \\
\hline & & $\begin{array}{c}\text { BRM } \\
(5)\end{array}$ & 477 & 8 & 0 & 0.0386 & 1.542 & 0.350 & $1 \times 10^{-5 \wedge}$ \\
\hline $\begin{array}{c}6,7,8 \\
\text { h1 }\end{array}$ & - - - - $001--$ & $\begin{array}{l}\text { DTE } \\
(7)\end{array}$ & 891 & 124 & 10 & 0.0125 & -0.297 & 0.083 & $0.0003^{\wedge}$ \\
\hline $\begin{array}{c}7,8,9 \\
\text { h2 }\end{array}$ & $-\ldots-\ldots 11-$ & $\begin{array}{l}\text { DTE } \\
(7)\end{array}$ & 734 & 156 & 0 & 0.0077 & -0.231 & 0.088 & 0.0087 \\
\hline $\begin{array}{c}7,8,9 \\
\text { h7 }\end{array}$ & - - - - - 101 - - & $\begin{array}{c}\text { BRM } \\
(5)\end{array}$ & 476 & 42 & 2 & 0.0128 & 0.380 & 0.147 & $0.0099 \wedge$ \\
\hline $\begin{array}{c}8,9,10 \\
\text { h2 }\end{array}$ & - - - - - $011-$ & $\begin{array}{c}\text { BRM } \\
(3)\end{array}$ & 477 & 42 & 2 & 0.0128 & 0.381 & 0.147 & $0.0097^{\wedge}$ \\
\hline $\begin{array}{c}8,9,10 \\
\text { h5 }\end{array}$ & $--\ldots-111-$ & $\begin{array}{c}\text { BRM } \\
(3)\end{array}$ & 6 & 98 & 417 & 0.0183 & -0.310 & 0.100 & $0.0020^{\wedge}$ \\
\hline $\begin{array}{c}8,9,11 \\
\text { h2 }\end{array}$ & $-----10-1$ & $\begin{array}{c}\text { BRM } \\
(5)\end{array}$ & 513 & 5 & 0 & 0.0261 & 1.651 & 0.444 & $0.0002^{\wedge}$ \\
\hline \multirow[t]{2}{*}{$\begin{array}{c}8,9,11 \\
\text { h3 }\end{array}$} & $-\ldots--11-0$ & $\begin{array}{l}\text { DTE } \\
(6)\end{array}$ & 538 & 332 & 8 & 0.0117 & -0.212 & 0.066 & $0.0013^{\wedge}$ \\
\hline & & $\begin{array}{c}\text { BRM } \\
(5)\end{array}$ & 8 & 102 & 408 & 0.0150 & -0.269 & 0.096 & $0.0053^{\wedge}$ \\
\hline $\begin{array}{c}9,10,11 \\
\text { h2 }\end{array}$ & $--_{-}---011$ & $\begin{array}{c}\text { BRM } \\
(5)\end{array}$ & 537 & 5 & 0 & 0.0233 & 1.596 & 0.444 & $0.0004 \wedge$ \\
\hline $\begin{array}{l}{ }^{1} \text { SNP ma } \\
\text { rs290236 } \\
2 \text { DTE - da } \\
{ }^{3} \text { N0 num } \\
\text { two copi } \\
{ }^{4} \text { Proport } \\
{ }^{5} \text { Haploty } \\
{ }^{6} \text { Standar } \\
\text { ^ Signific }\end{array}$ & $\begin{array}{l}\text { sed to generate } \\
\text { rs29023639, } 11 \\
\text { r experiment, BR } \\
\text { animals with zer } \\
\text { e haplotype. } \\
\text { residual variance } \\
\text { stitution effect i } \\
\text { of a. } \\
\text { er Bonferroni co }\end{array}$ & $\begin{array}{l}\text { haplotypes } \\
9014770) \text { a } \\
\text { Brahman ar } \\
\text { pies of the } \\
\text { olained by t } \\
\text { henotypic s } \\
\text { tion. }\end{array}$ & $\begin{array}{l}\text { - rs2902 } \\
\text { haplot } \\
\text { numbe } \\
\text { plotype } \\
\text { comm } \\
\text { ndard d }\end{array}$ & $\begin{array}{l}\text { 5-rs } \\
\text { umbe } \\
\text { ploty } \\
\text { umbe } \\
\text { lotyp } \\
\text { ns (ti }\end{array}$ & unt for & e DTE and ti & score for BF & and & nimals with \\
\hline
\end{tabular}


Experiments aimed at identifying genes that were differentially expressed in cattle with different tick resistance phenotypes, found evidence that collagen and other extracellular matrix genes were differentially expressed in the skin of cattle that are more resistant to tick infestation $[29,30]$.

\section{Conclusions}

Our analyses confirmed that there is a QTL affecting tick burden on BTA10. Significant common haplotypes were found that accounted for $1 \%$ of the residual variance and these haplotypes incorporated DNA variation from the ITGA11 gene. Whether the effects observed are due to variation in ITGA11 itself or are due to cis-effects of variation near ITGA11 regulating other genes will require indepth study of gene expression and function. Further analyses of SNP and other kinds of DNA variation in this region would be a first step toward identifying the causal alleles and elucidating the biological mechanism involved.

\section{Methods}

The analysis in the study follows a specific order. First, a selection of 32 putative SNP from BTA10 was genotyped in a collection of dairy taurine cattle, the dairy tick experiment (DTE). Fifteen of these putative SNP were monomorphic, which reduced the total available SNP to 17. Of these 17, 2 SNP were significant in the initial GWAS [20]. Second, 11 of these SNP were then genotyped in Brahman (BRM) and tropical composite (COM) beef cattle to extend and confirm the associations. As part of the analysis, single SNP as well as haplotype analyses were performed

\section{Tick phenotypes}

The animals, tick phenotypes and DNA samples were described previously $[8,9]$. In brief, the number of ticks on these animals (tick burden) was estimated in one of two ways. The DTE sample had field tick counts of individual ticks in the size range of $4.5-8 \mathrm{~mm}$ in diameter which represents mature ticks that will fall off the animal in the next 24 hours [4]. Ticks were counted on one side of the animal. The BRM and COM sample had tick burden estimates using tick scores. Tick scores are rapid estimates of tick burden of ticks that are $>4.5 \mathrm{~mm}$ in diameter. The tick scores are on a 0 - 5 scale where 0 is no ticks, 1 is $\leq 10$ ticks, 2 is $11-30$ ticks, 3 is $31-80$ ticks, 4 is 81 - 150 ticks, and $5>150$ ticks. Although tick scores are underestimates, are less accurate and they are also less informative, nevertheless there is a high genetic correlation between the two measurements [31]. Due to the unavailability of beef cattle with tick counts, we were constrained to using existing tick scores to confirm the associations that we had observed in the DTE.

\section{Animal samples}

In this experiment we used DNA samples from 1,055 DTE cattle that had $\geq 2$ tick counts. Animals were described in detail elsewhere [8]. In brief, the DTE cattle were from 16 properties across the tick zone in tropical and sub-tropical northeastern Australia. The sample consisted of animals of the Australian Red breed (AUR, $\mathrm{n}=$ 196), the Brown Swiss breed and its crosses (BSWX, $\mathrm{n}=$ 126), the Channel Isle breeds and their crosses (CHA, $n=$ 119), the Holstein breed and its crosses (HOLX, $\mathrm{n}=187$ ), composite taurine cattle (MIXT, $\mathrm{n}=424$ ) and composite taurine cattle with at least one grandparent of zebu ancestry (ZEBX, $\mathrm{n}=3)$. The previously published principal component analysis of genotypes of these taurine dairy cattle of pure and mixed ancestry could not put breeds into separate clusters or distinguish crossbreds from purebreds [32] so crossbreds were lumped with appropriate purebreds on the basis of known ancestry as previously described [8]. The average field tick counts for these animals was 47.1 ticks per side or an average $\ln ($ ticks +1$)$ of $3.03 \pm 1.29$ (s.d.) [8].

To confirm the associations we used 557 BRM and 216 COM animals that together form 773 Cooperative Research Centre (CRC2) animals with tick score data [33]. These cattle have been extensively described in a series of open access articles, see [33]. The COM animals were 50\% Bos taurus indicus, African sanga or other tropically adapted Bos taurus and 50\% non-adapted Bos taurus taurus. The animals with tick scores were bred on the Belmont and Swans Lagoon research stations for the summer of 2003/4 (December - February) and all were females with mean age of 34 months [9]. The average field tick score for BRM was 0.75 (s.d. = 0.74) and for COM was 2.26 (s.d. = 0.98) [9]. The adjustment of the phenotypic data was performed as previously specified [33].

\section{Analysis of tick data}

The association between each SNP and tick burden was assessed by a regression analysis of a residual phenotype on numbers of copies of a particular allele. To obtain the residual phenotype, trait values were fitted in a mixed model using the ASReml software [34] as follows: trait mean + fixed effects + animal + error, with animal and error fitted as random effects. For the DTE sample, the fixed effects of property, season and breed type were modelled as main fixed effects, where season included the identity of the counter and all tick counts of an animal were included indexed by season. All available pedigree information (sire, dam, grandsire and maternal grandsire identities) was included in the model. The residual effect of the animal was extracted for SNP regression analysis. For the CRC2 sample, the trait tick score was modelled with the fixed effects of breed, herd of origin, cohort, calving month and their first-degree interactions. Three 
generations of pedigree information was available. Residual trait values were extracted and used in SNP regression analyses. These models do not include the effects of DNA polymorphisms.

\section{SNP markers and genotypes}

A panel of SNP markers was genotyped over an $8.4 \mathrm{Mb}$ region of BTA10. The panel included 2 SNP (rs29025985 and rs29025981) significantly associated to tick burden in the GWAS [20], 9 SNP from the Baylor College of Medicine (BCM) interbreed database, 2 SNP from the Illumina BovineSNP50 and 16 SNP from the BCM bovine genome assembly database ftp://ftp.hgsc.bcm.tmc.edu/ pub/data/Btaurus/snp/Btau20050310/. To add to the number of SNP, and based on the SNP that had been significant in previous studies (rs29025985, rs29025981 and rs29025982), we sequenced PCR products of exons of the ITGA11 gene and the intronic sequence surrounding these exons. The cDNA sequence for ITGA11 (Genbank XM 602058.3) was compared to the cattle genome sequence using BLAST [35] to determine the splice sites of the gene. Primers to amplify exons 6 to 9 were designed, which correspond to the I-Domain of the protein [36]. Forward and reverse DNA sequence were obtained from four animals each of four breeds (Angus, Shorthorn, Holstein and Brahman). SNP were described using standard nomenclature [37]. SNP were submitted to dbSNP http://www.ncbi.nlm.nih.gov/snp and assigned identifiers (Additional file 1). SNP were genotyped using either GoldenGate (Illumina Inc., Hayward, California), SNPlex $^{\text {TM }}$ or TaqMan SNP Genotyping Assays (Applied Biosystems, Foster City, California) following the manufacturer's instructions with scoring performed by two individuals before genotypes were merged with phenotypes.

\section{Analyses of genotypic data}

The SNP genotypes were tested for Hardy-Weinberg equilibrium (HWE) within breed type using PLINK 1.05 [[38], http://pngu.mgh.harvard.edu/purcell/plink/]. The linkage disequilibrium (LD) between SNP was estimated using Haploview 4.1 [39] for DTE, BRM and COM individually. The haplotype block structure was obtained using the confidence interval method [40] implemented in Haploview 4.1. For association analyses, haplotypes were obtained using PHASE 2.1.1 [41,42]. We applied the PHASE algorithm five times for each set of SNP on animals without missing genotypes for the SNP in the haplotype. We also allowed PHASE to interpolate missing data and then evaluated the associations (Additional file 3). We evaluated a haplotype of all available SNP as well as a "sliding window" of haplotypes of three adjacent SNP (3locus haplotype), sliding one SNP at a time across the genomic region. Each 3-locus haplotype was named for the markers used to generate the haplotype plus the num- ber of the haplotype generated by these markers; e.g. haplotype 5,6,7 h1 was generated using the markers 5, 6 and 7 and this is the first haplotype (h1) of this set of markers. All haplotypes identified in this study are listed in additional file 4.

Association between each SNP or haplotype was evaluated by regression of the residual tick count or score on the number of copies of a reference allele. Allele associations were performed one SNP at a time. Significance was evaluated using a t-test of the slope of the regression over its standard error for each marker individually. For each haplotype, the individuals were scored for the number of copies of the haplotype they possessed, each haplotype was considered an independent event, analogous to analyses of DNA microsatellites [43], and the residual tick counts or scores were regressed on the number of copies of haplotypes analysed one at a time. A t-test was calculated by dividing the regression coefficient by its standard error. For association analyses of haplotypes the significance threshold was adjusted for multiple testing by Bonferroni correction, dividing the nominal 5\% significance threshold by the number of haplotypes inferred by PHASE for a set of SNP [43].

\section{Additional material}

\section{Additional file 1 Description of discovered SNP in the ITGA11 gene.}

Table describing the discovered SNP Btau 4.0 positions and dbSNP ss numbers.

Additional file $\mathbf{2}$ Linkage disequilibrium (LD) between markers at the ITGA11 gene region. Linkage disequilibrium (LD) between markers at the ITGA11 gene region.

Additional file 3 Eleven loci haplotype association with tick burden: interpolated missing data. Eleven loci haplotype association with tick burden using the interpolated missing data.

Additional file 4 Description of the haplotypes reconstructed using 10 loci and the 3-locus sliding window. Description of the haplotypes reconstructed using 10 loci and the 3 -locus sliding window.

\section{Authors' contributions}

LRPN and WB planned the experiments and wrote the manuscript. LRPN analyzed the genotypic data, RJB and BEH collected DNA samples. LRPN, RJB and $\mathrm{BEH}$ genotyped the animals. LRPN identified SNP by DNA sequencing, KCP defined the beef cattle phenotypes. All authors read and approved the final manuscript.

\section{Acknowledgements}

We thank N. Jonsson for discussing tick resistance, W. Barris for mapping SNP into the Btau4.0 assembly and L.B. Turner and the Australian Dairy Herd Information Service for providing the pedigree records. S.A. Lehnert, J.M. Henshall and A. Reverter commented on a draft of the manuscript. LRPN is supported by an Endeavour International Postgraduate Research Scholarship, a University of Queensland International Student Living Allowance and a Beef CRC scholarship. This research was co-funded by the Beef $C R C$ in grants to KCP and WB and the collection of the Dairy animals was co-funded by Dairy Australia (WB)

\section{Author Details}

${ }^{1}$ Cooperative Research Centre for Beef Genetic Technologies, University of New England, Armidale, NSW 2351, Australia, ${ }^{2}$ CSIRO Livestock Industries, Queensland Bioscience Precinct, 306 Carmody Road, St. Lucia, QLD 4067 Australia and ${ }^{3}$ The University of Queensland, School of Animal Studies, St Lucia, QLD 4072, Australia 
Received: 13 October 2009 Accepted: 21 June 2010

Published: 21 June 2010

\section{References}

1. Minjauw B, McLeod A: Tick-borne diseases and poverty. The impact of ticks and tick-borne diseases on the livelihoods of small-scale and marginal livestock owners in India and eastern and southern Africa. Research Report, DFID Animal Health Programme, Centre for Tropical Veterinary Medicine, University of Edinburgh, UK; 2003.

2. Jongejan F, Uilenberg G: The global importance of ticks. Parasitology 2004, 129:S3-S14

3. deCastro JJ: Sustainable tick and tickborne disease control in Livestock improvement in developing countries. Veterinary Parasitology 1997, 71(2-3):77-97

4. Wharton RH, Utech KBW, Turner HG: Resistance to cattle tick, Boophilusmicroplus in a heard of Australian Illawarra Shorthorn cattle - its assessment and heritability. Australian Journal of Agricultural Research 1970, 21(1):163.

5. Mackinnon MJ, Meyer K, Hetzel DJS: Genetic-variation and covariation for growth, parasite resistance and heat tolerance in tropical cattle. Livestock Production Science 1991, 27(2-3):105-122.

6. Burrow HM: Variances and covariances between productive and adaptive traits and temperament in a composite breed of tropical beef cattle. Livestock Production Science 2001, 70(3):213-233.

7. Prayaga KC, Henshall JM: Adaptability in tropical beef cattle: genetic parameters of growth, adaptive and temperament traits in a crossbred population. Australian Journal of Experimental Agriculture 2005, 45(78):971-983.

8. Turner LB, Harrison BE, Bunch RJ, Porto Neto LR, Li YT, Barendse W: A genome wide association study of tick burden and milk composition in cattle. Animal Production Science 2010, 50:235-245

9. Prayaga KC, Corbet NJ, Johnston DJ, Wolcott ML, Fordyce G, Burrow HM: Genetics of adaptive traits in heifers and their relationship to growth, pubertal and carcass traits in two tropical beef cattle genotypes. Animal Production Science 2009, 49(5-6):413-425.

10. Utech KBW, Wharton RH, Kerr JD: Resistance to Boophilus-microplus (Canestrini) in different breeds of cattle. Australian Journal of Agricultural Research 1978, 29(4):885-895.

11. Frisch JE, O'Neill CJ: Comparative evaluation of beef cattle breeds of African, European and Indian origins. 2. Resistance to cattle ticks and gastrointestinal nematodes. Animal Science 1998, 67:39-48.

12. da Silva AM, de Alencar MM, de Almeida LC Regitano, de Sena Oliveira MC, Barioni W: Artificial infestation of Boophilus microplus in beef cattle heifers of four genetic groups. Genetics and Molecular Biology 2007 30(4):1150-1155.

13. Stear MJ, Hetzel DJ, Brown SC, Gershwin LJ, Mackinnon MJ, Nicholas FW: The relationships among ectoparasite and endoparasite levels, class I antigens of the bovine major histocompatibility system, immunoglobulin E levels and weight gain. Veterinary Parasitology 1990, 34(4):303-321.

14. Stear MJ, Nicholas FW, Brown SC, Holroyd RG: Class I antigens of the bovine major histocompatibility system and resistance to the cattle tick (Boophilus microplus) assessed in three different seasons. Veterinary Parasitology 1989, 31(3-4):303-315.

15. Acosta-Rodrigez $\mathrm{R}$, Alonso-Morales $\mathrm{R}$, Balladares $\mathrm{S}$, Flores-Aguilar $\mathrm{H}$, Garcia-Vazquez Z, Gorodezky C: Analysis of BoLA class II microsatellites in cattle infested with Boophilus microplus ticks: class II is probably associated with susceptibility. Veterinary Parasitology 2005, 127(34):313-321.

16. Martinez ML, Machado MA, Nascimento CS, Silva MV, Teodoro RL, Furlong J, Prata MC, Campos AL, Guimaraes MF, Azevedo AL, et al:: Association of BoLA-DRB3.2 alleles with tick (Boophilus microplus) resistance in cattle. Genetics and Molecular Research 2006, 5(3):513-524.

17. Untalan PM, Pruett JH, Steelman CD: Association of the bovine leukocyte antigen major histocompatibility complex class II DRB3*4401 allele with host resistance to the Lone Star tick, Amblyomma americanum. Veterinary Parasitology 2007, 145(1-2):190-195.

18. Regitano LCA, Ibelli AMG, Gasparin G, Miyata M, Azevedo ALS, Coutinho LL, Teodoro RL, Machado MA, Silva M, Nakata LC, et al:: On the Search fo Markers of Tick Resistance in Bovines. In Animal Genomics for Animal
Health Volume 132. Edited by: Pinard MH, Gay C, Pastoret PP, Dodet B. Basel: Karger; 2008:225-230.

19. Gasparin G, Miyata M, Coutinho LL, Martinez ML, Teodoro RL, Furlong J, Machado MA, Silva M, Sonstegard TS, Regitano LCA: Mapping of quantitative trait loci controlling tick [Riphicephalus (Boophilus) microplus] resistance on bovine chromosomes 5, 7 and 14. Animal Genetics 2007, 38(5):453-459.

20. Barendse $W$ : Assessing tick resistance in a bovine animal for selecting cattle for tick resistance by providing a nucleic acid from the bovine animal and assaying for the occurrence of a single nucleotide polymorphism (SNP). Patent application WO2007051248-A1 2007:1-146.

21. Elsik CG, Tellam RL, Worley KC, Gibbs RA, Muzny DM, Weinstock GM, Adelson DL, Eichler EE, Elnitski L, Guigo R, et al.: The genome sequence of taurine cattle: a window to ruminant biology and evolution. Science 2009, 324(5926):522-528.

22. Porto Neto LR, Barendse W: Automated SNP calling overestimates the number of SNP in the bovine genome. Proceedings of the Conference of the International Society for Animal Genetics Amsterdam 2008, 1:3 [http:// www.isag.org.uk/conferences past.asp]. checked at 11/06/2010

23. MacHugh DE, Shriver MD, Loftus RT, Cunningham P, Bradley DG: Microsatellite DNA variation and the evolution, domestication and phylogeography of taurine and Zebu cattle (Bos taurus and Bos indicus). Genetics 1997, 146(3):1071-1086.

24. Pritchard JK: Are rare variants responsible for susceptibility to complex diseases? American Journal of Human Genetics 2001, 69(1):124-137.

25. Willadsen P: Immunity to ticks. Advances in Parasitology 1980 18:293-311

26. Inokuma H, Kerlin RL, Kemp DH, Willadsen P: Effects of cattle tick (Boophilus-microplus) infestation on the bovine immune-system. Veterinary Parasitology 1993, 47(1-2):107-118.

27. Gibbs RA, Taylor JF, Van Tassell CP, Barendse W, Eversole KA, Gill CA, Green RD, Hamernik DL, Kappes SM, Lien S, et al:: Genome-wide survey of SNP variation uncovers the genetic structure of cattle breeds. Science 2009, 324(5926):528-532.

28. Coelho LFL, Mota BEF, Sales PCM, Marques JT, de Oliveira JG, Bonjardim CA, Ferreira PCP, Kroon EG: Integrin alpha 11 is a novel type I interferon stimulated gene. Cytokine 2006, 33(6):352-361

29. Kongsuwan K, Piper EK, Bagnall NH, Ryan K, Moolhuijzen P, Bellgard M Lew A, Jackson L, Jonsson NN: Identification of Genes Involved with Tick Infestation in Bos taurus and Bos indicus. In Animal Genomics for Animal Health Volume 132. Edited by: Pinard MH, Gay C, Pastoret PP, Dodet B. Basel: Karger; 2008:77-88.

30. Wang YH, Reverter A, Kemp D, McWilliam SM, Ingham A, Davis CK, Moore RJ, Lehnert SA: Gene expression profiling of Hereford Shorthorn cattle following challenge with Boophilus microplus tick larvae. Australian Journal of Experimental Agriculture 2007, 47(12):1397-1407.

31. Fraga AB, Alencar MMd, Fiqueiredo LAd, Razook AG, Cyrillo JNdSG: Analise de fatores geneticos e ambientais que afetam a infestacao de femeas bovinas da raca Caracu por carrapatos (Boophilus microplus). Revista Brasileira de Zootecnia 2003, 32:1578-1586.

32. Barendse W, Harrison BE, Bunch RJ, Thomas MB, Turner LB: Genome wide signatures of positive selection: The comparison of independent samples and identification of regions associated to traits. BMC Genomics 2009, 10:178.

33. Barwick SA, Johnston DJ, Burrow HM, Holroyd RG, Fordyce G, Wolcott ML, Sim WD, Sullivan MT: Genetics of heifer performance in 'wet' and 'dry' seasons and their relationships with steer performance in two tropical beef genotypes. Animal Production Science 2009, 49(5-6):367-382

34. Gilmour AR, Gogel BJ, Cullis BR, Welham SJ, Thompson R: ASReml User Guide Release 1.0. VSN International Ltd, Hemel Hempstead, HP1 1ES, UK; 2002.

35. Altschul SF, Gish W, Miller W, Myers EW, Lipman DJ: Basic Local Aligment Search Tool. Journal of Molecular Biology 1990, 215(3):403-410.

36. Takada Y, Ye XJ, Simon S: The integrins. Genome Biology 2007, 8(5):

37. den Dunnen JT, Antonarakis SE: Mutation nomenclature extensions and suggestions to describe complex mutations: A discussion. Human Mutation 2000, 15(1):7-12

38. Purcell S, Neale B, Todd-Brown K, Thomas L, Ferreira MAR, Bender D, Maller J, Sklar P, de Bakker PIW, Daly MJ, et al.: PLINK: A tool set for wholegenome association and population-based linkage analyses. American Journal of Human Genetics 2007, 81(3):559-575. 
39. Barrett JC, Fry B, Maller J, Daly MJ: Haploview: analysis and visualization of LD and haplotype maps. Bioinformatics 2005, 21(2):263-265.

40. Gabriel SB, Schaffner SF, Nguyen H, Moore JM, Roy J, Blumenstiel B, Higgins J, DeFelice M, Lochner A, Faggart M, et al: The structure of haplotype blocks in the human genome. Science 2002, 296(5576):2225-2229.

41. Stephens M, Smith NJ, Donnelly P: A new statistical method for haplotype reconstruction from population data. American Journal of Human Genetics 2001, 68(4):978-989.

42. Stephens M, Scheet P: Accounting for decay of linkage disequilibrium in haplotype inference and missing-data imputation. American Journal of Human Genetics 2005, 76(3):449-462.

43. Pritchard JK, Rosenberg NA: Use of unlinked genetic markers to detect population stratification in association studies. American Journal of Human Genetics 1999, 65(1):220-228.

doi: 10.1186/1471-2156-11-55

Cite this article as: Porto Neto et al., Haplotypes that include the integrin alpha 11 gene are associated with tick burden in cattle BMC Genetics 2010, 11:55

Submit your next manuscript to BioMed Central and take full advantage of:

- Convenient online submission

- Thorough peer review

- No space constraints or color figure charges

- Immediate publication on acceptance

- Inclusion in PubMed, CAS, Scopus and Google Scholar

- Research which is freely available for redistribution

Submit your manuscript at www.biomedcentral.com/submit
C) Biomed Central 